5 Research Square

\title{
A simple kinetic modelling of coronavirus infection in a system
}

NaaderAlizadeh ( $\nabla$ alizaden@modares.ac.ir)

TarbiatModares University

Research Article

Keywords: COVID-19, kinetic modelling, prediction of infection

Posted Date: June 2nd, 2020

DOI: https://doi.org/10.21203/rs.3.rs-30383/v1

License: (c) (i) This work is licensed under a Creative Commons Attribution 4.0 International License. Read Full License 


\title{
A simple kinetic modelling of coronavirus infection in a system
}

\author{
NaaderAlizadeh
}

Department of Chemistry, Faculty of Basic Sciences, TarbiatModares University, P.O. Box 14115-175, Tehran, Iran

In this paper, provide an analysis of data on the characteristics of patients with confirmed COVID-19 infection throughout Iran and other countries such as China, S. Korea,USA, Italy, Spain, Germany, France, UK, Austria, and Argentina, and presented a kinetic modelling for prediction of infection, death, recovery and patients populations. The predict results of infection, death and recovery rate constants helps to interpret of public sentiment on disseminating related health information, and comparison different governments behavior to overcoming the outbreak of the coronavirus (COVID-19). Calculation results are in agreement with the census data of the coronavirus infection in many regions of the world.

E-mail address: alizaden@modares.ac.ir (N. Alizadeh).

Keywords: Kinetic modelling, COVID-19, Coronavirus, Prediction, Analysis 
Since December 2019, novel pneumonia cases were reportedin China. ${ }^{1}$ Thesecases have been identified as infections with a novel strain of coronavirus, called COVID-19 by the World Health Organization (WHO) ${ }^{2-6}$ In January 2020, the coronavirus spread over China and reached to other countries.Daily situation contain the infection and death cases were reported by WHO from January 21.

Commonsymptoms include fever, coughand shortness of breath. Other symptoms may include fatigue,muscle pain, diarrhea, sore throat, loss of smell and abdominal pain. While the majority of cases result in mild symptoms, some progress to viral pneumonia and multi-organ failure. ${ }^{7}$

In 19 February 2020, first cases of coronavirusinfectionsin Iran werereported fromQom province. ${ }^{8}$ The number of infection cases to COVID-19 have spreadexponentially since March, 2020 in most countries in Europe and USA. As of 16 April 2020, more than 2 millioncases have been reported in more than 200 countries and territories, resulting in more than 95,800 deaths and more than 542,000 people have recovered. ${ }^{9}$

For many researchers and specialists it is crucial to understand the time profile of infection population. Therefore, analysis and modelling can inform predictions about potential future growth of infection.

Lin and et al. utilize Susceptible-Exposed-Infectious-Recovered (SEIR) modelling to forecast COVID-19 outbreak within and outside of China based on daily observations. ${ }^{10}$ Kucharski and co-workers reported a mathematical modelling study for dynamics of transmission and control of COVID-19. ${ }^{11}$ Leungprovide an impact assessment of the transmissibility and severity of COVID-19 during the first wave in mainland Chinese locations outside Hubei. ${ }^{12}$ AlsoBayham used data from the monthly releases of the US Current Population Survey to characterize the 
family structure and probable within-household child-care options of US health-care workersby a modelling analysis. ${ }^{13}$ Koo and co-workerswere adapted an influenza epidemic simulation model to estimate the likelihood of human-to-humantransmission of severe acute respiratory syndrome coronavirus 2 in a simulated Singaporean population. ${ }^{14}$

In this work, kinetic modelling of coronavirus infection has been provided based on an autocatalytic behavior. The proposed model was used for data on cases of coronavirus disease (COVID-19) in China as a sample. The number of infection, death, recovery and patients (timeprofile) were predicted for China cases by provided model. With regarding to very good adaptationof calculated and census data, model were used for Iran and other countries to estimate how transmission had varied over time during in January, 2020, and April, 2020.

\section{Modelling}

The scheme 1 shows an autocatalysis reaction, which is just the appearance of one of the products of the reaction as a reactant in the same (HV) or a coupled reaction. The following kinetic model (Scheme 1) adapted to coronavirus infection which can depict the dynamic of infection, recovery and death processes in one and two steps (one-wave and two-waves). In this model $\mathrm{H}, \mathrm{HV}, \mathrm{R}$ and $\mathrm{D}$ are number of health, infected,recovered and death cases, respectively. The mass balance and rate expressions equations of each component are given by Eqs. (1)-(6). 


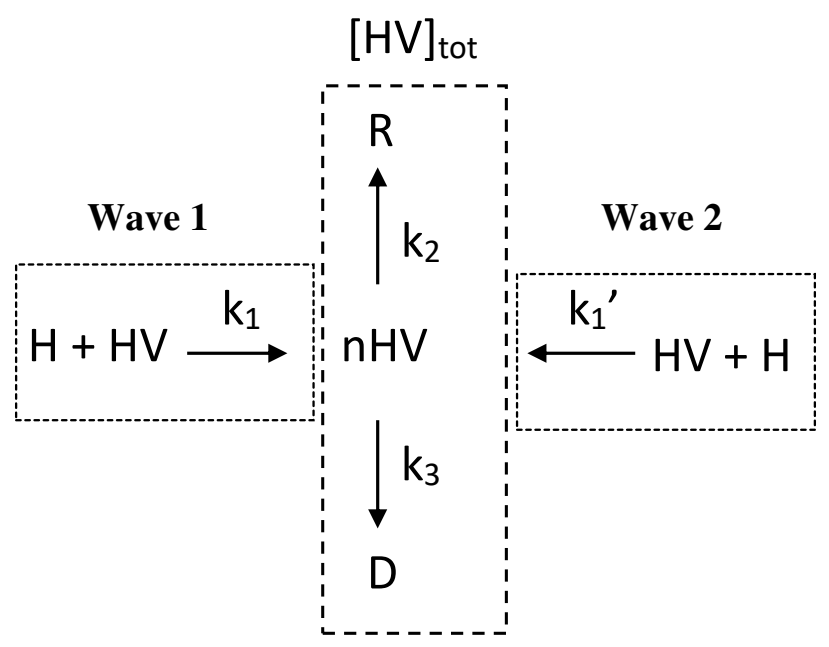

Scheme 1:One and two-wave infection scheme.

$$
\begin{aligned}
& {\left[\mathrm{H}_{0}\right]-[\mathrm{H}]=[\mathrm{HV}]-\left[\mathrm{HV}_{0}\right]} \\
& {[\mathrm{H}]=[\mathrm{X}]} \\
& {[\mathrm{HV}]_{\text {tot }}=\left[\mathrm{H}_{0}\right]+\left[\mathrm{HV}_{0}\right]-[\mathrm{X}]} \\
& \mathrm{d}[\mathrm{X}] / \mathrm{dt}=\mathrm{k}_{1}[\mathrm{X}]\left(\left[\mathrm{H}_{0}\right]+\left[\mathrm{HV}_{0}\right]-[\mathrm{X}]\right) \\
& \mathrm{d}[\mathrm{R}] / \mathrm{dt}=\mathrm{k}_{2}[\mathrm{HV}] \\
& \mathrm{d}[\mathrm{D}] / \mathrm{dt}=\mathrm{k}_{3}[\mathrm{HV}] \\
& {[\mathrm{HV}]_{\mathrm{tot}}=[\mathrm{HV}]+[\mathrm{D}]+[\mathrm{R}]}
\end{aligned}
$$

By dividing Eq.(6) to Eq.(5), Eq.(8) is obtained:

$[\mathrm{D}]=[\mathrm{R}] \cdot \mathrm{k}_{3} / \mathrm{k}_{2}$ 
where $\left[\mathrm{H}_{0]},\left[\mathrm{HV}_{0}\right]\right.$ are the initial number of health and infected cases, $[\mathrm{HV}]_{\text {totand }}[\mathrm{HV}]$ are total number of infected and patients cases([P]), $\mathrm{k}_{1}, \mathrm{k}_{2}$ and $\mathrm{k}_{3}$ are infection, recovery and death rate constants, respectively.By solving the differential Eq.(4):

$\ln \left(\left[\mathrm{H}_{0}\right] \cdot[\mathrm{HV}] /\left[\mathrm{HV}_{0}\right] .[\mathrm{H}]\right) /\left(\left[\mathrm{H}_{0}\right]+\left[\mathrm{HV}_{0}\right]\right)=-\mathrm{k}_{1} . \mathrm{t}$

or

$[\mathrm{HV}]_{\mathrm{tot}}=\mathrm{A} /\left\{1+\mathrm{B} \cdot \exp \left(-\mathrm{k}_{1} \cdot \mathrm{A} \cdot \mathrm{t}\right)\right\}$

where $\mathrm{A}=\left[\mathrm{H}_{0}\right]+\left[\mathrm{HV}_{0}\right]$ and $\mathrm{B}=\left[\mathrm{H}_{0}\right] /\left[\mathrm{HV}_{0}\right]$

Equation (10) shows of number of infected-time profile with the sigmoid function behavior.

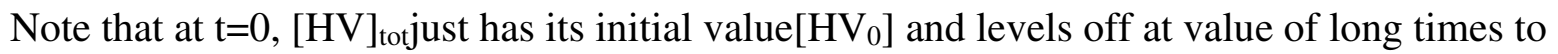
$\left[\mathrm{H}_{0}\right]+\left[\mathrm{HV}_{0}\right]$

The number of recovery cases can be obtained by solving Eq.(5). By rearrangement of Eq.(7) and substituting in Eq.(5),Eq.(11) is obtained:

$\mathrm{d}[\mathrm{R}] / \mathrm{dt}=\mathrm{k}_{2} \cdot\left([\mathrm{HV}]_{\mathrm{tot}^{-}}[\mathrm{D}]-[\mathrm{R}]\right)$

As can be seen from Eq.(11), the solving of differential equation seems to be difficult. Thus, by considering theassumption given in Eq.(12) and Eq.(8), Eq. (11) can be alteredto Eq.(13). 
$[\mathrm{R}]=\alpha .[\mathrm{HV}]_{\mathrm{tot}}(12)$

$\mathrm{d}[\mathrm{R}] / \mathrm{dt}=[\mathrm{HV}]_{\text {tot. }}\left(\mathrm{k}_{2}-\alpha \cdot\left(\mathrm{k}_{3}+\mathrm{k}_{2}\right)\right)$

By substituting Eq.(10) in Eq.(13) and solving it, Eq.(14) is obtained:

$[R]=\left(k_{2}-\alpha\left(k_{2}+k_{3}\right)\right) \cdot\left\{\left(\ln \left(B \cdot \exp \left(-k_{1} \cdot A \cdot t\right)-\ln (B+1)\right) / k_{1}+\right.\right.$ A.t $\}$

With assumption similar to Eq.(12),[D] can be calculated by Eq.(15).

$[D]=\left(k_{3}-\beta\left(k_{2}+k_{3}\right)\right) \cdot\left\{\left(\ln \left(B \cdot \exp \left(-k_{1} \cdot A \cdot t\right)-\ln (B+1)\right) / k_{1}+A \cdot t\right\}\right.$

or $[\mathrm{D}]=\beta \cdot[\mathrm{HV}]_{\mathrm{tot}}(16)$

By dividing Eq.(16) to Eq.(12), and substituting to Eq.(8), Bis obtained:

$\beta=\alpha \cdot k_{3} / k_{2}(17)$

where $\alpha$ and $\beta$ are recovery and death fraction, respectively.

According to Eq.(7), Eq.(8), Eq.(10) and Eq.(14), number of patients can be calculating byEq.(18):

$[\mathrm{P}]=[\mathrm{HV}]_{\mathrm{tot}}[\mathrm{R}]-[\mathrm{D}]$ 
The values of A, B and $\mathrm{k}_{1}$ can be estimated by rearrangement of Eq.(10) and substituting firstderivative of Eq.(10), Eq.(21) is obtained:

$$
\begin{aligned}
& {[\mathrm{HV}]_{\mathrm{tot}}+(\mathrm{B} / \mathrm{A}) \cdot \exp \left(-\mathrm{k}_{1} \cdot \mathrm{A} \cdot \mathrm{t}\right)=\mathrm{A}} \\
& \left(\mathrm{d}[\mathrm{HV}]_{\mathrm{tot}} / \mathrm{dt}\right) /\left([\mathrm{HV}]_{\text {tot }}^{2} \cdot \mathrm{k} 1 \cdot \mathrm{A} \cdot\right)=\mathrm{B} \cdot \exp \left(-\mathrm{k}_{1} \cdot \mathrm{A} \cdot \mathrm{t}\right) \\
& {[\mathrm{HV}]_{\mathrm{tot}}=\left\{\left(\mathrm{d}[\mathrm{HV}]_{\mathrm{tot}} / \mathrm{dt}\right) / \mathrm{k}_{1} \cdot \mathrm{A}\right\}+[\mathrm{HV}]_{\text {tot }}^{2} / \mathrm{A}(21)}
\end{aligned}
$$

By fitting of Eq.(21) in term of $[\mathrm{HV}]_{\mathrm{tot}} v s .[\mathrm{HV}]_{\text {tot }}^{2}$ in time interval that first derivative of function is constant ( $\mathrm{t}<$ rise time to $\mathrm{t} \leq$ levels off time), $\mathrm{A}$ and $\mathrm{k}_{1}$ can be estimate from slope and interceptof regression.

The peak time or $\mathrm{t}_{50 \%}$ can be estimate by Eq.(22) for a single sigmoid function:

$\mathrm{t}_{50 \%}=(\ln \mathrm{B}) /\left(\mathrm{k}_{1} . \mathrm{A}\right)$

With regarding to second wave of infection is probableafterthe first wave of infection, a twowave model is shown in Scheme 1.In Scheme 1, $\mathrm{k}_{1}$ 'isinfection rate constant in second wave. The governing equations of the two-wave infection model are as follows:

$$
[\mathrm{HV}]_{\mathrm{tot}}=\mathrm{A}_{1} /\left\{1+\mathrm{B}_{1} \cdot \exp \left(-\mathrm{k}_{1} \cdot \mathrm{A}_{1} \cdot \mathrm{t}\right)\right\}+\mathrm{A}_{2} /\left\{1+\mathrm{B}_{2} \cdot \exp \left(-\mathrm{k}_{1} \cdot \mathrm{A}_{2} \cdot \mathrm{t}\right)\right\}
$$


where all variables are the same as for Eqs. (1-14), with the subscripts 1 and 2referring to the two different kinetic waves.Two-wave model assumes that the total infection number on the infection process can be divided into twofractions with different rats and various coefficientsand infection rate constants. The initial conditions areattime $=0$ :

$[\mathrm{HV}]_{0}=\mathrm{A}_{1} /\left(1+\mathrm{B}_{1}\right)+\mathrm{A}_{2} /\left(1+\mathrm{B}_{2}\right)$

$\mathrm{A}_{1}=\left[\mathrm{H}_{01}\right]+\left[\mathrm{HV}_{0}\right] \quad$ and $\mathrm{A}_{2}=\left[\mathrm{H}_{02}\right]$

$\mathrm{B}_{1}=\left[\mathrm{H}_{01}\right] /\left[\mathrm{HV}_{0}\right]$ and $\mathrm{B}_{2}=\left[\mathrm{H}_{02}\right] /\left[\mathrm{HV}_{0}\right]$

andatthe long times, levels off times:

$[\mathrm{HV}]_{\mathrm{tot}}=\left[\mathrm{H}_{01}\right]+\left[\mathrm{H}_{02}\right]+\left[\mathrm{HV}_{0}\right](27)$

where $\left[\mathrm{H}_{01}\right]$ and $\left[\mathrm{H}_{02}\right]$ are number of infection cases in wave 1 and wave 2 , respectively.

\section{Analysisandmodel validation}

To show the feasibility of the proposed model for the description of coronavirus infection in a system, the number of infection, recovery, death, and patients of China as a sample set of data was used to compare with predictions by the model. Data is extracted from verified sources. ${ }^{15-}$ ${ }^{17}$ The aim of this calculation was to demonstrate that model can be used to predict infection-time profiles over wider range of time. The Eq.(10) have three unknown parameters, which should be estimated: $\mathrm{A}=$ maximum number of infection, $\mathrm{B}=$ relative health cases that can be infected by other infected cases to initial infected cases, and $\mathrm{k}_{1}=$ infection rate constant in first wave.The quasi first order infection rate constant $\left(\mathrm{k}_{1}\right.$.A) was estimated by the first-order conditional 
estimation extended least squares method. This parameter was obtained from the slope of $\ln$ (number of infection cases)vs. time plot inthe time interval, where $\mathrm{t} \geq$ rise time (Fig. S1).The intercept of plot estimate the natural logarithm of the initialinfection number ([HV $\left.\left.\mathrm{HV}_{0}\right]\right)$. The maximum number of infection $\left(A_{\max }\right)$, can also be estimated by Eq.(19). In time interval that variation of cumulative infected number is linear vs. time, we can use slope of this dependency for fitting of Eq. (19) by a linear regression for estimation of A and $\mathrm{k}_{1}$ from slope and intercept, respectively (Fig.S2).Kinetic estimated parameters are given in Table 1.Then refinements were obtained by choosingthe best fitsof proposed infection-time profiles by using the Excel Solver program.Kinetic parameters of Eqs.(7-15) such as $\mathrm{k}_{1}, \mathrm{k}_{2}, \mathrm{k}_{3}$ and $\beta$ were computedby using least squares curve fit method for thegiven number of infection, recovery, death and patient cases, and which are given in Table 1.

In order to assess the performance of the obtained kinetic model, the number of infected coronavirus calculated from Eq.(10) were compared whit the infection census data for China and is indicated in Fig. 1a.A comparison between thecensus data and predicated data indicates a very good correlation coefficientsof kinetic model $\left(\mathrm{R}^{2}=0.94-0.99\right)$. The number of recovery, death and patient cases were also calculated from equations Eq.(14), Eq. (15) and Eq.(18), respectively and compared whit the corresponding census data in Fig.1b, Fig.1c, and Fig.1d, respectively.The calculated kinetic parameters regression using kinetic model is summarized in Table 1.

An additional set of data containing infected,recovery,deathand patients cases for other countries such as S. Korea, Iran, USA, Italy, China, Spain, Germany, France, UK, Austriaand Argentina were used to compare with predictionsof the kinetic model.Kinetic estimated parameters of 
different countries are given in Table 1 . Themodel was fitted with all the available census data(before17 April, 2020)and kinetic parameters areshown in Table 1.

Figs. 2a show fits obtained using the one-wave infection model for S. Korea.As can be seen from Figs. 2a, the one-wave infection model does not completely describe the end part of infection curve. While the one-wave model predicts a plateau phase in long times, census datadisplay amore gradual increase of the later part of the tail.The two-wave model, Eq. (23) did fit the overall shape of the infection curvesvery well (Figs. 2b).Apparently, we will in anticipation of a possible second wave in S. Korea. Results of the calculationof the infected,recovery,death and patient cases for S. Korea are shown in Fig. 2a, Fig.2b,Fig.2c, Fig.2d and Fig.2e, respectively.

Similarly as, the one wave model was used in predicting the number of coronavirus infection in Iran.When calculating the number of patients in Iran and other countries, the infected numbertime profiles have not yet reached to their final values (plateau phase).

A typically, comparison of predicted and infection census data for Iran and USA are also shown in Fig. 3(a-d) and Fig.4(a-d). The excellent match between the census and predicted results for different countriesindicates that the proposed kinetic model in Scheme 1 represents the coronavirus infection satisfactorily.The results of prediction and calculated kinetic parameters are summarized in Table 1.

\section{Discussion}

Comparing results of model predict with census infection cases reported in China, show that the model predict good agreements results with census data reported before 17 April, 2020. The model also did predict the infection time-profile of other countries in different regions of the world.Typical results of observation and predicted infection-time profiles for other countries are 
shown in Fig. 2(a-e), Fig. 3(a-d) and Fig.4(a-d) and supporting information figures. Whit the exception of S. Korea, other countries fit by one-wave kinetic model.

The results demonstrate that best fitting obtained for infection-time profiles $\left(R^{2} \geq 0.98\right)$ while death-time profiles fitted by lower correlation coefficients $\left(0.90 \leq \mathrm{R}^{2}<0.98\right)$. In some case such as Germany and Australia calculation death- time profile has a similar trend to observed data with a time delay. A time shift about 7-11 days caused improve correlation coefficient of fitting(Fig.S9c and 9c').The main assumption of this kinetic model is the individual behaviors and governmental action, effect on kinetic parameters and is not affected on model validity.

As summarized in Table 1, the infection rate constants values $\left(\mathrm{k}_{1}\right)$ obtained by fitting of kinetic model cannot be compared simply for different countries. Therefore, for better comparison, a first order infection rate constant is obtained from the multiplication of $100 \mathrm{k}_{1}$ in $\mathrm{A}_{\text {cal }}$ where used as "corona". A corona unit is defined 100 case/(day.case). According to corona unit definition, the highest value of first order infection rate constant belong to S. Korea and then to China. However, the highest value of first order recovery rate constantis also belongs to S. Korea.

The highest and lowest values of first order death rate constant belong to France and USA, respectively. However, the lowest value of first order recovery rate constant is also belongs to USA.

In conclusion,kinetic modelling of coronavirus infectionbased on autocatalytic chemical reaction idea can be applied for simulation of infection casesthat originated in a system to estimate how transmission had varied over time during and not depended to region of infection. The merit of our model is that we predicted some essential parameters, including maximum number of infection, first and second order infection rate constants, recovery, death rate constants, 
recovery and death fractions and plateau time of infection. Meanwhile, proposed model is relatively simple and our estimates for different countries are in good agreements with census data at during selected times.However, individual behaviors and governmental action, effect on deviation of calculation and census data, but these values compensate by kinetic parameters and is not affected on validity of model.

\section{References:}

1. Lu, H., Stratton, C.W., Tang, Y. Outbreak of pneumonia of unknown etiology in Wuhan China: the mystery and the miracle, J. Med. Virol. 25678 (2020).

2. WHO. Coronavirus disease 2019 (COVID-19). Situation report 24. February 13, 2020. Geneva: World Health Organization, 2020.

3. nCoV-2019 Data working group. Epidemiological data from the nCoV-2019 outbreak: early descriptions from publicly available data. 2020 . http://virological.org/t/epidemiological-data-from-the-ncov-2019-outbreak-earlydescriptions-from-publicly-available-data/337 (accessed Feb 13, 2020).

4. National Health Commission of the People's Republic of China. The updated news of COVID-19 as of 24 February 2020. 2020 24:00;. Online; http://www.nhc.gov.cn/yjb/s7860/202002/67e6c59a84bd4f07b6ca4a4c5ffabb79.shtml (accessed 25.02.20).

5. World Health Organization, WHO Director-General's Remarks at the Media Briefingon 2019-nCoV on 11 February 2020, (2020). https://www.who.int/dg/speeches/detail/whodirector-general-s-remarks-at-the-media-briefing-on-2019-ncov-on-11-february-2020.

6. Sohrabi, C., et al. World Health Organization declares global emergency: A review of the 2019novel coronavirus (COVID-19). Int. J. Surg. 76, 71-76 (2020). 
7. WHO, "Advice for Public," WHO Int., 2020. [Online]. Available: https://www.who.int/emergencies/diseases/novel-coronavirus-2019/advice-for-public. [Accessed 27 February 2020].

8. "Iran Reports Its First 2 Cases of the New Coronavirus". New York Times. Archived from the original on 19 February 2020. Retrieved 19 February 2020.

9. "Coronavirus COVID-19 Global Cases by the Center for Systems Science and Engineering (CSSE) at Johns Hopkins University (JHU)". ArcGIS. Johns Hopkins CSSE. Retrieved 9 April 2020.

10. Lin, Q., et al., A conceptual model for the coronavirus disease 2019 (COVID-19) outbreak in Wuhan, China with individual reaction and governmental action, Int $J$ Infect Dis.93, 211-216(2020).

11. Li, Q., et al. Early transmission dynamics in Wuhan, China, of novelcoronavirus-infected pneumonia, N. Engl. J. Med. 382, (2020) 1199-1207.doi:10.1056/NEJMoa2001316.

12. Leung, K., Wu, J.T.,Liu, D., Leung, G. M. First-wave COVID-19 transmissibility and severity in China outside Hubei after control measures, and second-wave scenario planning: a modelling impact assessment. Lancet, Published online April 8, 2020 https://doi.org/10.1016/S0140-6736(20)30746-7.

13. Bayham, J., Fenichel, E.P.Impact of school closures for COVID-19 on the US health-care workforce and net mortality: a modelling study workforce and net mortality: a modelling study. The Lancet, published online April 3, 2020 https://doi.org/10.1016/S24682667(20)30082-7. 
14. Koo, J. R.,et al. Interventions to mitigate early spread of SARS-CoV-2 in Singapore: a modelling study.TheLancet, infection published online March 23, 2020 https://doi.org/10.1016/S1473-3099(20)30162-6.

15. WHO,Coronavirus disease (COVID-2019) situation reports. https://www.who.int/emergencies/diseases/novel-coronavirus-2019/situation-reports

16. Worldmeter. Coronavirus Cases_Statistics and Charts - Worldometer. [Internet]. 2020;2020 Disponible a: https://www.worldometers.info/coronavirus/.

17. CFS and SEJHU, 2020, Center for Systems Science and Engineering Johns Hopkins University, CSSEGISandData/COVID-19 (April 2020) Available from https://github.com/CSSEGISandData/COVID-19.

\section{Acknowledgements}

This work dedicated to all coronavirus victims in the world.Financial support from the Research Council of TarbiatModaresUniversity and Iran National Science Foundation (INSF) is gratefullyacknowledged. The author thanksHussein Gharibi for helpful comments andSaeed Aghamiri for help to conversion of census reports to Excel data.

\section{Author Contributions}

N.A. analyzed dataand wrote the manuscript.

\section{Additional Information}

Supplementary information accompanies this paper at http://www.nature.com/srep

Competing financial interests: The authors declare no competing financial interests 


\section{Figures}
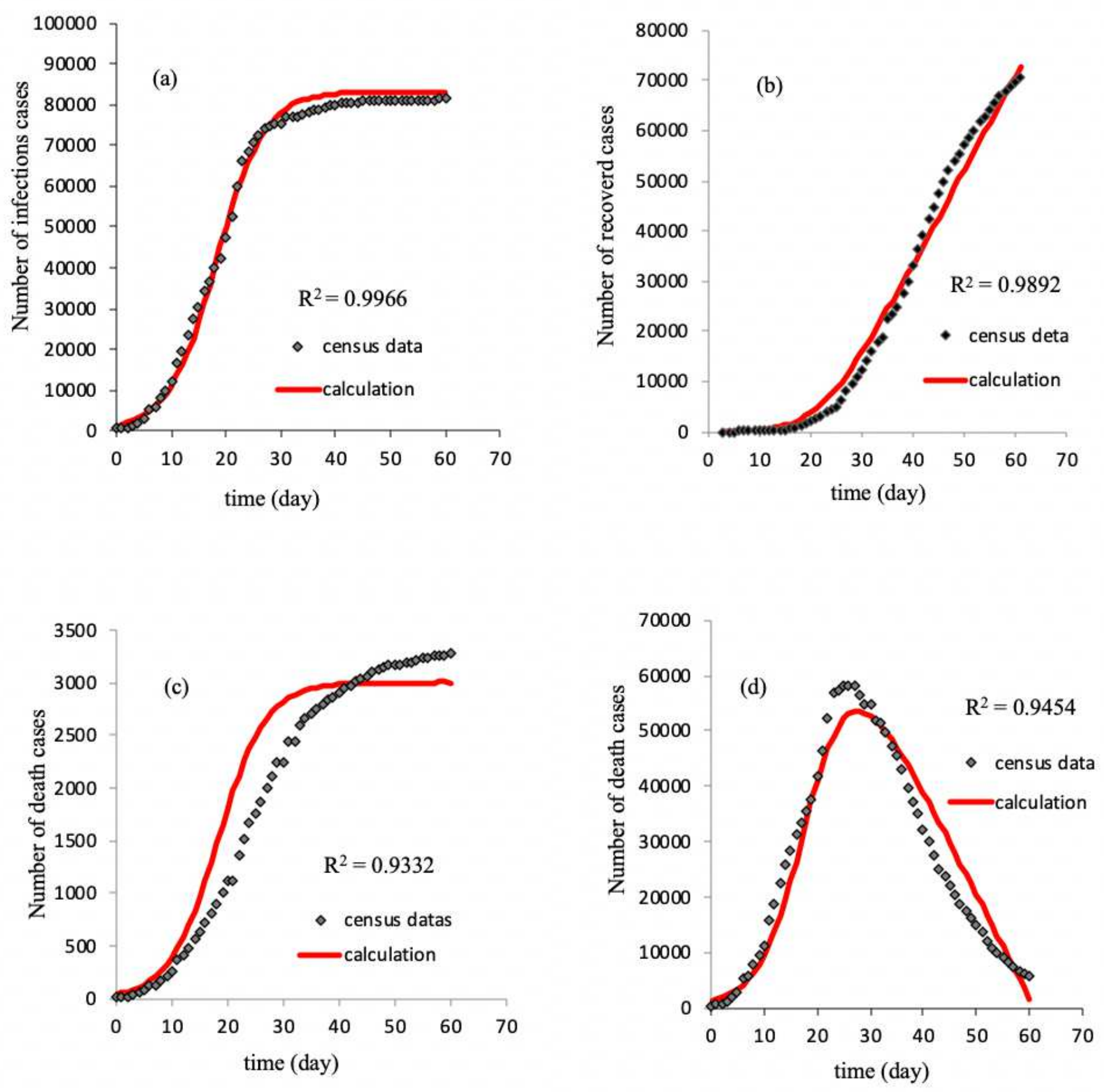

\section{Figure 1}

The number of cases-time profiles for the infection (a), recovery (b), death (c) and patients(d), with the symbols representing the census dataand lines representing the predicted results using kinetic model for China (Jan. 22 - Mar. 22, 2020). 

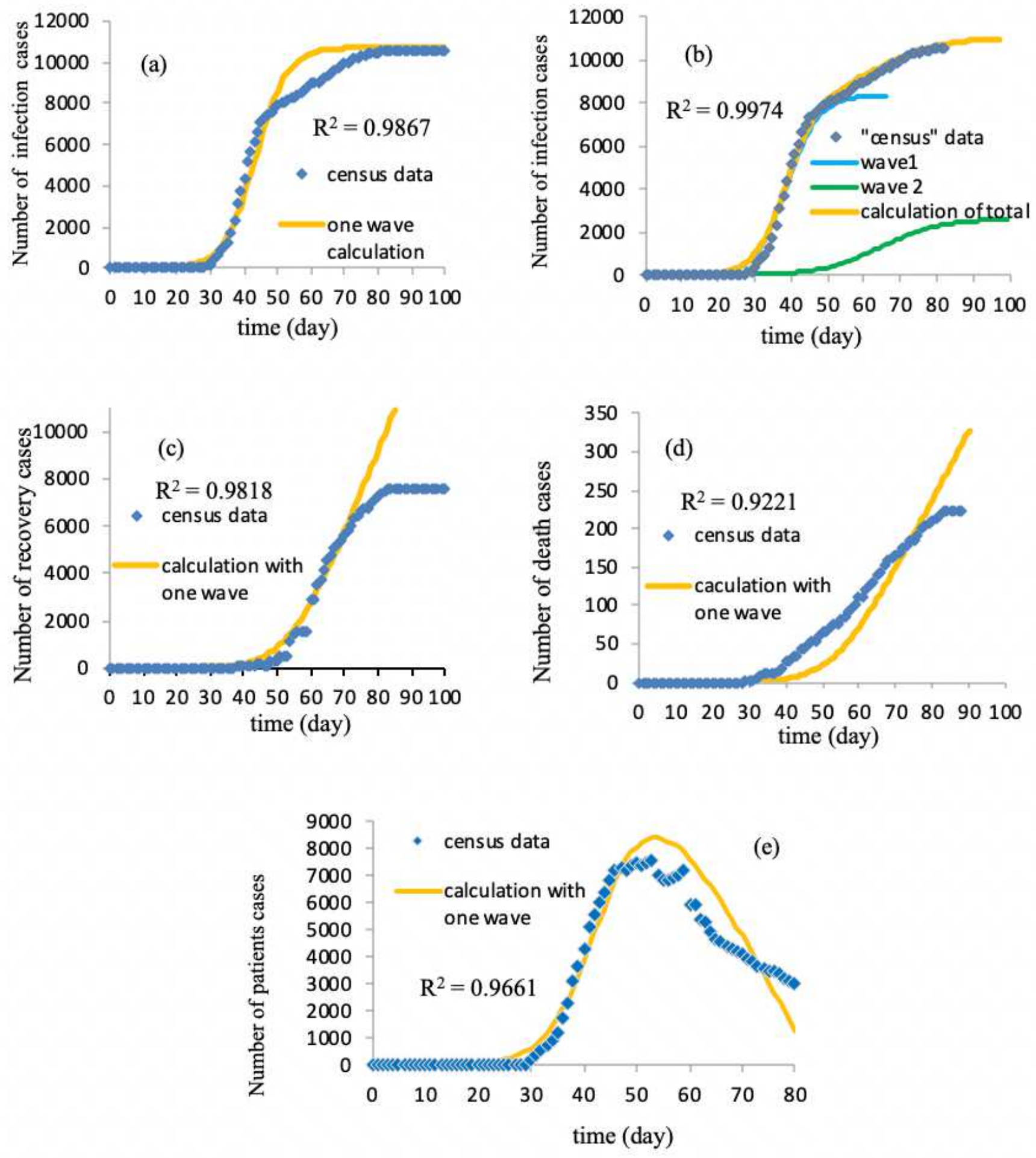

\section{Figure 2}

The number of cases-time profiles for the infection (a) for one wave and (b) for two wave, recocery (c), death (d) and patients(e), with the symbols representing the census dataand lines representing the predicted results using kinetic model for S. Korea (Jan. 22 - Mar. 11, 2020). 

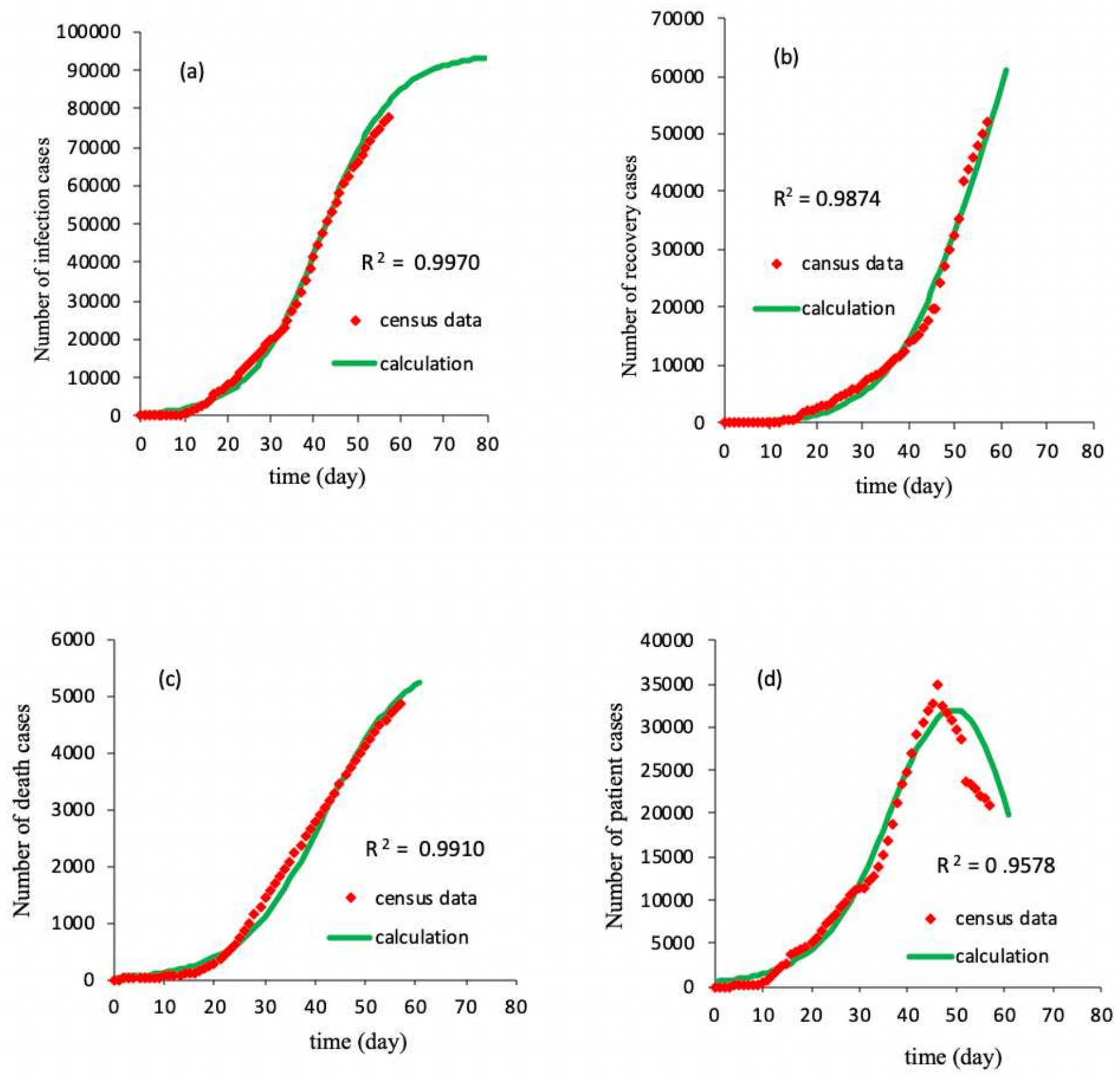

Figure 3

The number of cases-time profiles for the infection (a), recovery (b), death (c) and patients(d), with the symbols representing the census dataand lines representing the predicted results using kinetic model for Iran (Feb. 19 - Apr. 16, 2020). 

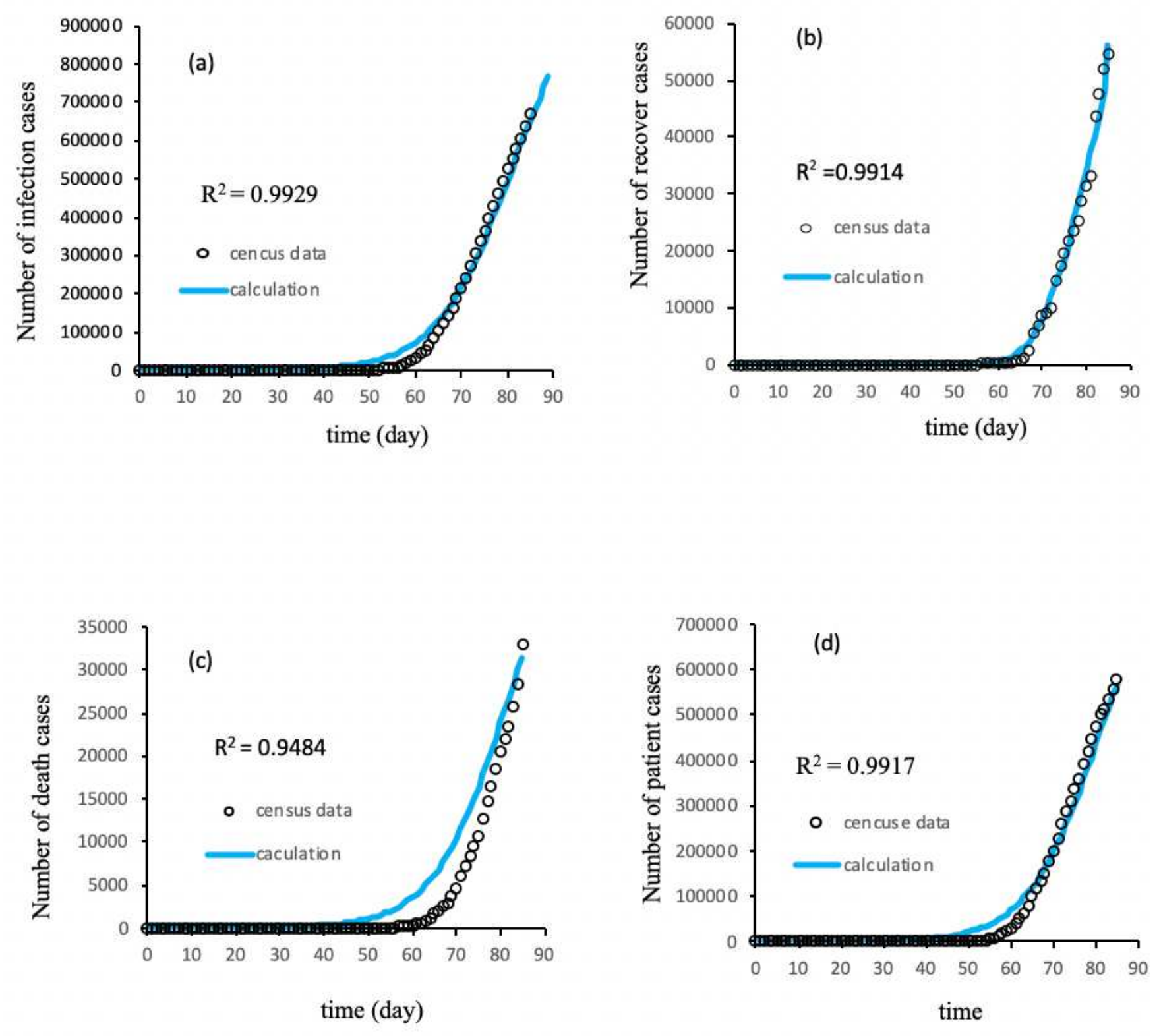

\section{Figure 4}

The number of cases-time profiles for the infection (a), recovery (b), death (c) and patients(d), with the symbols representing the census dataand lines representing the predicted results using kinetic model for USA (Jan. 22 - Apr. 16, 2020).

\section{Supplementary Files}

This is a list of supplementary files associated with this preprint. Click to download.

- SupportinginformationSR.docx 